\title{
Myocardial rupture in acute myocardial infarction: urgent management
}

\author{
DOV STRYJER, AHARON FRIEDENSOHN, ALBERTO HENDLER \\ From the Heart Institute, Assaf Harofe Medical Center, Zerifin, Tel Aviv University Sackler School of \\ Medicine, Tel Aviv, Israel
}

SUMMARY Myocardial rupture complicated acute myocardial infarction in a 50 year old man. Resuscitation was started immediately and he was treated with pericardiocentesis and a massive intravascular infusion of fluid. The torn area was plicated with Teflon felt and reinforced with an uninterrupted suture. The postoperative course was uncomplicated.

This report points out the crucial importance of prompt clinical recognition and management of the acute stage of cardiac rupture in acute myocardial infarction.

Rupture of the free wall of the left ventricle complicating acute myocardial infarction is a common cause of in-hospital death. Predisposing factors, clinical presentation, and pathological features have been reported extensively. ${ }^{1}$ Despite its prevalence management of myocardial rupture is usually ineffective with only a few successes reported. ${ }^{23}$

\section{Case report}

A 50 year old man was admitted to the intensive coronary care unit of a community hospital with chest pain in association with weakness and dyspnoea. He had a history of hypertension treated by atenolol $100 \mathrm{mg}$ daily.

On admission the patient was pale and anxious. His blood pressure was $110 / 80 \mathrm{~mm} \mathrm{Hg}$ and the pulse rate 100 beats $/ \mathrm{min}$. On auscultation of the chest no rales were heard in either lung. The heart sounds were diminished and there was no atrial or ventricular gallop rhythm. No heart murmurs were heard. The peripheral pulses were normal. The electrocardiogram showed an extensive anterior myocardial infarction. The chest $x$ ray was normal.

Four hours after arrival at the unit, while he was complaining of severe, crushing pain, the patient

Requests for reprints to Dr Dov Stryjer, Heart Institute, Assaf Harofe Medical Center, 70300 Zerifin, Israel. suddenly lost consciousness. There was respiratory arrest, pronounced jugular venous distension, and his face and neck became purple. The peripheral pulses were unpalpable. The monitoring lead showed extreme sinus bradycardia and no heart sounds were heard. In the light of the clinical evidence of acute cardiac tamponade, resuscitation was started immediately. Pericardiocentesis was performed and a massive infusion of fluid was started. The pericardial puncture yielded $300 \mathrm{ml}$ of unclotted blood. Progressively, the blood pressure and respiration reappeared. Almost simultaneously the patient recovered consciousness. There was a positive Kusmaull sign and a paradoxical pulse.

A ruptured heart complicating an acute myocardial infarction was diagnosed and the patient was transferred to a centre for cardiovascular surgery and immediately moved to the operating room.

At operation, clots and unclotted blood were removed from the pericardial sac and a hole was identified in the apical area to the left of the left anterior descending coronary artery. This torn area was plicated by Teflon felt and reinforced with uninterrupted sutures. The postoperative course was uncomplicated.

Cross sectional echocardiography and equilibrium radionuclide angiography were performed 10 days after operation. The echocardiogram from a modified apical long axis view (two chamber view) 
showed a clearly delineated, lacerated area, which sharply interrupted the endocardial surface echoes, in the apical segment of the left ventricle free wall. This zone was dyskinetic when compared with the nearly normal function of the posterior left ventricular wall, and it was thin throughout the cardiac cycle, as has previously been described in similar cases. ${ }^{4}$

Angiography was performed after labelling the patient's red blood cells in vivo with $3 \mathrm{mg}$ of intravenous stannous pyrophosphate; twenty minutes later $20 \mathrm{mCi}$ of technetium-99 pertechnetate was injected. Images were recorded in both the anterior and $45^{\circ}$ left anterior oblique projections, which best define the interventricular septum. The angiograms showed a global left ventricular ejection fraction of $27 \%$, with akinesis of the anteroseptal wall and a dyskinetic apical segment. The posterolateral wall function was normal.

\section{Discussion}

Rupture of the free wall of the left ventricle complicating an acute myocardial infarction may be classified as three clinical types: acute, subacute, and chronic. ${ }^{5}$ The acute type is characterised by the rapid development of mechanical arrest at the onset of the rupture of the free wall associated with sinus bradycardia which is followed by a slow atrioventricular junction rhythm. This may be explained, at least in part, by vagal stimulation of afferent nerves originating from the pericardial receptors. The subacute type presents with signs and symptoms resembling cardiogenic shock and the patient can survive a few hours, which permits additional diagnostic procedures (for example echocardiography). The chronic type is characterised by the formation of a pseudoaneurysm. In the subacute type the diagnosis may be completed by rapid echocardiographic demonstration of direct and indirect signs of cardiac rupture, followed by pericardiocentesis, intravascular volume repletion, and surgical repair. Survival in this condition depends on prompt surgical intervention or the rare development of a pseudoaneurysm.

Our patient had the acute type of cardiac rupture with a clinical picture of mechanical cardiac arrest. The immediate pericardiocentesis showed the presence of blood in the pericardial sac, permitting a prompt diagnosis and the introduction of intrapericardial drainage accompanied by massive intravascular fluid repletion. This approach produced a dramatic haemodynamic improvement so that the patient could be transferred to another hospital for urgent cardiac surgery.

This report emphasises the crucial importance of prompt clinical recognition of the acute stage of cardiac rupture associated with acute myocardial infarction. Immediate pericardiocentesis, with no delay for other diagnostic procedures, meant that urgent surgical intervention could be attempted.

Successful repair of ventricular rupture may be followed by long term survival, ${ }^{6}$ as it was in our patient (eight months).

\section{References}

1 Bates RJ, Beutler S, Resnekov L, Anagnostopoulus CE. Cardiac rupture: challenge in diagnosis and management. Am J Cardiol 1977;40:429-37.

2 Abel RM, Buckley MJ, Friedlich AL, Austen WG. Survival following free rupture of left ventricular aneurysm. Report of a case. Ann Thorac Surg 1976;21:175-9.

3 Cobbs BW, Hatcher CR, Robenson PH. Cardiac rupture: three operations with two long term survivals. JAMA 1973;223:532-5.

4 Hermoni Y, Engel PJ. Two-dimensional echocardiography in cardiac rupture. Am J Cardiol 1986;57:180-1.

5 Bashour T, Kabbani S, Ellertson D, Crew J, Hanna E. Surgical salvage of heart rupture: report of two cases and review of the literature. Ann Thorac Surg 1983;36:209-13.

6 Feneley MP, Chang VP, O'Rourke MF. Myocardial rupture after acute myocardial infarction. Ten year review. Br Heart J 1983;49:550-6. 